
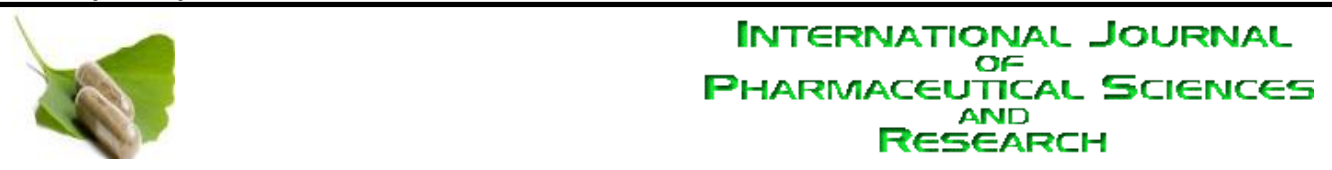

Received on 27 February, 2011; received in revised form 18 April, 2011; accepted 08 May, 2011

\title{
AN APPROACH FOR IMPROVEMENT OF THE WATER SOLUBILITY OF GLICLAZIDE IN SOLID DISPERSION WITH PEG 4000
}

Tarun Garg

Department of Pharmaceutics, ISF College of Pharmacy, Moga, Punjab, India

\begin{tabular}{|c|c|}
\hline & ABSTRACT \\
\hline $\begin{array}{l}\text { Keywords: } \\
\text { Solid dispersions, } \\
\text { Solvent-melting, } \\
\text { Wettability, } \\
\text { Dispersibility }\end{array}$ & $\begin{array}{l}\text { Gliclazide is a second-generation hypoglycaemic sulfonylurea that is useful in the } \\
\text { treatment of Type } 2 \text { diabetes mellitus. It shows low aqueous solubility and } \\
\text { dissolution rate and often shows low and irregular bioavailability after oral } \\
\text { administration. This paper describes an approach to improve the Solubility of } \\
\text { gliclazide by using solid dispersions (SDs) in polyethylene glycol } 4000 \text { (PEG 4000). }\end{array}$ \\
\hline $\begin{array}{l}\text { ondence to Author: } \\
\text { arg } \\
\text { ent of Pharmaceutics, ISF } \\
\text { of Pharmacy, Moga, } \\
\text { India }\end{array}$ & $\begin{array}{l}\text { Solid dispersions were prepared by a solvent-melting method and Solubility } \\
\text { determinations were performed in triplicate according to the method of Higuchi } \\
\text { and Connors. The solubility of gliclazide is } 0.86 \mathrm{mg} / \mathrm{ml} \text { in water but after the } \\
\text { addition of different concentration of PEG } 4000, \text { the solubility of gliclazide is } \\
\text { increased maximum } 3.07 \mathrm{mg} / \mathrm{ml} \text { at } 20 \% \mathrm{w} / \mathrm{v} \text { of PEG } 4000 \text {, was observed. The } \\
\text { main conclusion of this article is that the solubility of gliclazide can be enhanced } \\
\text { in Solid Dispersion with PEG } 4000 \text {. The solubilization effect of PEG } 4000 \text {, } \\
\text { reduction of particle aggregation of the drug, absence of crystallinity, increased } \\
\text { wettability and dispersibility, and alteration of surface properties of the drug } \\
\text { particles may be responsible for the enhanced solubility of gliclazide from its } \\
\text { Solid Dispersion. }\end{array}$ \\
\hline
\end{tabular}

Correspondence to Author:

Tarun Garg

Department of Pharmaceutics, ISF College of Pharmacy, Moga,

Punjab, India water-soluble drugs in water-soluble polymers enhances drug solubility and its bioavailability ${ }^{5}$.

The preparation and characterization of complexes of gliclazide with $\beta$-cyclodextrin ${ }^{6-8}$, complexation of gliclazide with $\beta$-cyclodextrinhydroxypropyl methyl cellulose, which enhanced its hypoglycemic activity ${ }^{9}$, accelerated absorption of gliclazide using PEG $400{ }^{10}$, Solid dispersions of gliclazide in PEG 6000 have been developed to increase drug dissolution rate ${ }^{11}$, Enhancement of the solubility of gliclazide using polyvinylpyrrolidone $\mathrm{K} 9 \mathrm{O}^{12}$ have been reported. The molecular weight of the polymer may play a role in the performance of a solid dispersion. The rationale of the present study was to investigate the use of lower molecular weight PEG 4000 for the preparation of solid 
dispersions with the objectives of improving solubility and its bioavailability of gliclazide.

\section{MATERIALS AND METHODS:}

Materials: A gift sample of Gliclazide was received from Bal Pharma Ltd. (Mumbai, India). PEG 4000 was received from Central Drug House (P) Ltd. (New Delhi, India). Double-distilled water was used throughout the study, and all other chemicals were of analytical grade.

Preparation of Solid Dispersions: The solid dispersions were prepared by a solvent-melting method using different concentrations $(0-20 \% \mathrm{w} / \mathrm{v})$ of PEG 4000 . In the solvent-melting method, the required amount of PEG 4000 was melted in a glass container on a heating mental maintained at a temperature of about 50$60^{\circ} \mathrm{C}$. The required amount of gliclazide $(1 \% \mathrm{w} / \mathrm{v})$ solution in chloroform was prepared and added to the molten PEG 4000 and mixed thoroughly with a glass rod for $15 \mathrm{~min}$. The glass container was placed in deep freezer at $-70^{\circ} \mathrm{C}$ for 1 day; the mixture cooled rapidly and solidified. The solidified mixture was then powdered in a mortar, sieved through an 85-mesh screen, and stored in a screw-cap vial at room temperature until use.

Solubility determinations of Gliclazide: Solubility determinations were performed in triplicate according to the method of Higuchi and Connors ${ }^{13}$. An excess amount of gliclazide and solid dispersion of different concentration of PEG 4000 was placed in a separate glass beaker, which contain $10 \mathrm{~mL}$ of an aqueous solution, until saturation. The samples were shaken at $37 \pm 0.5^{\circ} \mathrm{C}$ for $24 \mathrm{~h}$ in a shaking incubator (Lab tech, Daihan Labtech Co., Ltd.) at $100 \mathrm{rpm}$. After $24 \mathrm{~h}$, the samples were filtered through a filter paper. The filtrate was suitably diluted and analyzed spectrophotometrically at $227 \mathrm{~nm}$ using a UV-vis spectrophotometer (Shimadzu UV-1700, Pharm Spec).

\section{RESULTS:}

Solubility Studies: The solubility behaviour of gliclazide from solid dispersion, which have $0-20 \%$ (w/v) PEG 4000 compositions, showed an increased solubility (Table 1). Maximum solubility of gliclazide $3.07 \pm 0.04$ $\mathrm{mg} / \mathrm{ml}$ was observed at $20 \% \mathrm{w} / \mathrm{v}$ PEG 4000 concentration (Figure 1).
TABLE 1: EFFECT OF PEG 4000 CONCENTRATION ON GLICLAZIDE SOLUBILITY

\begin{tabular}{|c|c|c|}
\hline $\begin{array}{l}\text { Concentration of } \\
\text { gliclazide }(\% \mathrm{w} / \mathrm{v})\end{array}$ & $\begin{array}{l}\text { Concentration of } \\
\text { peg } 4000(\% w / v)\end{array}$ & $\begin{array}{l}\text { Gliclazide solubility at } \\
37^{\circ} \mathrm{c}(\mathrm{mg} / \mathrm{ml})\end{array}$ \\
\hline 1 & 0 & $0.86 \pm 0.05$ \\
\hline 1 & 2 & $0.87 \pm 0.07$ \\
\hline 1 & 4 & $1.11 \pm 0.06$ \\
\hline 1 & 6 & $1.36 \pm 0.04$ \\
\hline 1 & 8 & $1.57 \pm 0.05$ \\
\hline 1 & 10 & $1.79 \pm 0.03$ \\
\hline 1 & 12 & $2.08 \pm 0.02$ \\
\hline 1 & 14 & $2.30 \pm 0.04$ \\
\hline 1 & 16 & $2.62 \pm 0.09$ \\
\hline 1 & 18 & $2.77 \pm 0.05$ \\
\hline 1 & 20 & $3.07 \pm 0.04$ \\
\hline
\end{tabular}

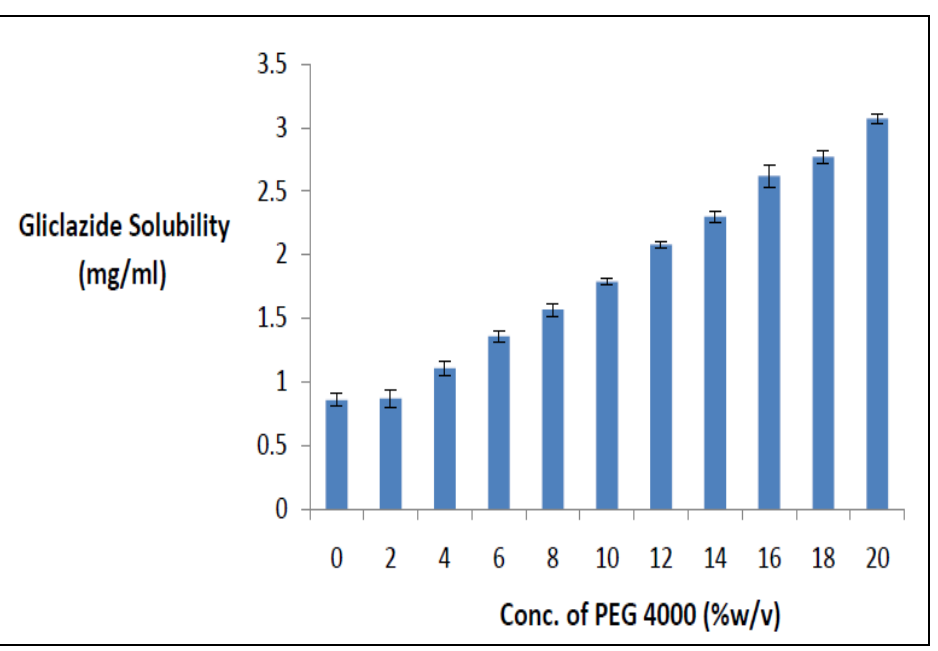

FIG. 1: EFFECT OF PEG 4000 CONCENTRATION ON GLICLAZIDE SOLUBILITY (WITH ERROR BAR)

CONCLUSION AND DISCUSSION: The solubility of gliclazide can be enhanced in Solid Dispersion with PEG 4000. The solubilization effect of PEG 4000, reduction of particle aggregation of the drug, absence of crystallinity, increased wettability and dispersibility, and alteration of surface properties of the drug particles may be responsible for the enhanced solubility of gliclazide from its Solid Dispersion. It can be concluded that gliclazide SDs with PEG 4000 provide a promising way to enhance its solubility.

ACKNOWLEDGMENTS: The authors are grateful to Bal Pharma Ltd., (Mumbai, India), and Central Drug House (P) Ltd. (New Delhi, India) for their interest and for supplying gliclazide and polyethylene glycol, respectively. Mr. P. Garg acknowledges the Chairman, ISF College of Pharmacy, Moga, for providing the necessary facilities. 


\section{REFERENCES:}

1. Reynolds JEF: Martindale: The Extra Pharmacopoeia XXX. Pharmaceutical Press: London. 1993;30:279-280.

2. Dollery SC: Therapeutic Drugs; Churchill Livingstone: London. 1991.

3. Harrower AD: Comparison of efficacy, secondary failure rate and complications of sulfonylurea. J. Diabetes Complicat. 1994; 8:201-203.

4. Palmer $\mathrm{KJ}$ and Brogden RN: Gliclazide, an update of its pharmacological properties and therapeutic efficacy in NIDDM. Drugs. 1993; 46:92-125.

5. Ford JL: The current status of solid dispersions. Pharm. Acta Helv. 1986; 61:69-88.

6. Özkan Y, Atay T, Díkman N, Isimer A and Aboul-Enein YH: Improvement of water solubility and in vitro dissolution rate of gliclazide by complexation with $\beta$-cyclodextrin. Pharm. Acta Helv. 2000; 74:365-370.

7. Winters $S$, York $P$ and Timmins $P$ : Solid state examination of a gliclazide: beta-cyclodextrin complex. Eur. J. Pharm. Sci. 1997; 5: 209-214.
8. Sapkal NP, Kilor VA, Bhusari KP and Daud AS: Evaluation of some Methods for preparation of gliclazide- $\beta$-cyclodextrin inclusion complexes. Trop. J. Pharm. Res. 2007; 6 (4):833-840.

9. Aggarwal S, Singh PN and Mishra B. Studies on solubility and hypoglycemic activity of gliclazide beta-cyclodextrinhydroxypropylmethylcellulose complexes. Pharmazie. 2002; 57: 191-193.

10. Hong SS, Lee SH, Lee YJ, Chung SJ, Lee MH and Shim CK. Accelerated oral absorption of gliclazide in human subjects from a soft gelatine capsule containing a PEG 400 suspension of gliclazide. J. Controlled Release. 1998; 51:185-192.

11. Biswal S, Sahoo J, Murthy PN, Giradkar PR and Avari JG. Enhancement of dissolution rate ofgliclazide using solid dispersions with polyethylene glycol 6000. AAPS PharmaSciTech. 2008; 9(2):563-570.

12. Biswal S, Sahoo J and Murthy PN. Physicochemical Properties of Solid Dispersions of Gliclazide in PolyvinylpyrrolidoneK-90. AAPS PharmSciTech. 2009; 10(2):329-334.

13. Higuchi T and Connors K. Phase-solubility techniques. Adv. Anal. Chem. Instrum. 1965; 4: 117-123. 